\title{
Prospects for the use of wood waste for the production of heavy-duty wood boards
}

\author{
Egor Zagrebin*, and Konstantin Vedernikov \\ Udmurt State University, Universitetskaya Str., 1, 426034 Izhevsk, Russia
}

\begin{abstract}
The article presents materials on the prospects of processing wood waste into high-strength structural cellulose material using alkaline processing of raw materials followed by hot pressing. Materials on the study of the cellulose-lignin complex and non-structural components of wood on the example of coniferous plants of various life conditions, including dead wood, are presented. Differences in the content of extractive substances (non-structural components) in individuals of different living conditions, which have a significant impact on the chemical treatment of wood, were revealed. The possibility of using white rotting wood-destroying fungi for partial delignification of wood is considered. The study was carried out with the financial support of the RFBR grant No. 19-04-00353 A.
\end{abstract}

\section{Introduction}

Polymeric and metal construction materials with high physical and mechanical characteristics have either large weight and suffer from environmental hazards (metal corrosion), or suffer from complex production processes and, consequently, high cost (polymeric). Wood is a cheap and widespread natural material, and it has been used as construction material in everyday life for ages. However, physical and mechanical properties of natural wood are inferior to many modern construction materials. Preliminary processing with steam, heat, ammonia, or cold reduction with subsequent packing led to the increase of natural wood mechanical properties [1-4]. However, the existing methods lead to incomplete packing and insufficient stability of linear dimensions, especially in high humidity conditions. With regard of active development of construction industry and farsighted use of the existing resources, the goal of our study is developing new technical solutions in the field of wood processing, allowing the use of raw materials base to the full extent, including the active involvement of wood waste.

Wood is a complex polymeric compound. And, in distinction from synthetic construction materials, it is characterized by environmental friendliness and abundance. At the same time, it is inferior to artificial materials in such an important indicator as strength. Certainly, polymeric and biopolymeric materials (CCB, chipboard, OSB, decking, etc.), characterized by high longevity and high strength, are actively used today. The approach proposed will not, possibly, become a full replacement of the existing materials, but it can substantially improve the existing technologies in terms of strength of materials obtained.

*Corresponding author: i.am.yeti@yandex.ru 
Coniferous wood (except fir tree, yew, and juniper), the most frequently used in the construction field, is penetrated by resin channels, representing channels, filled with resin, that penetrate wood both in vertical and horizontal directions. The basis of coniferous wood is cell wall, consisting in the beginning of formation from cellulose and hemicelluloses. Cellulose fusiform bodies are deposited on the primary membrane from the cell cavity side. Solidification of cell membranes also occurs due to their lignification, due to lignin production. The complex non-carbohydrate polymer, lignin, adds to cell membranes strength and rigidity, as well as an ability to resist to mechanical action [5-8].

Today, wood is considered as bionanocomposite, based on polysaccharide components (cellulose and hemicellulose) and aromatic polyfunctional polymer, lignin. During the wood biosynthesis, involving environmental factors, a lignin-carbohydrate complex is formed, the structure and properties of which determine the behavior of plant polymers at diverse effects $[9,10]$.

In connection with this, natural wood is a porous structural compound, therefore, it has a low specific weight and penetrating power. However, at the same time, porosity reduces the wood strength. In this regard, it is required to carry out wood pressing with the purpose to remove cavities from it. In this case, wood permeability will decrease, but at the same time, its strength will increase, without adding adhesives, and deformation of the obtained material from ambient temperature and moisture variations will almost disappear.

\section{Materials and Methods}

The studies were conducted on the territory of the Udmurt Republic, located in the European part of Russia, in Kama and Vuyatka river basins [11]. Predominant forests in Udmurtia are fir forests, occupying an area of 790.7 ths. ha, making up $35.2 \%$ from all woods in the region [12].

Sprucewood required less hard processing in plasticization of structural components (especially lignin), and is characterized by less wood loss (4-9\% for coniferous species, 5$12 \%$ for broadleaved species) and high strength factors [13]. Thereby, the study of wood chemical properties was carried out using Siberian spruce wood (Picea obovata Ledeb.).

For potential development of technological solutions in the field of processing of both wood timber and wood waste, sprucewood of different condition (good, satisfactory and unsatisfactory vital condition) was sampled for chemical analyses.

Preparation of wood samples to biochemical analysis included wood disintegrating and moisture content determination for calculation of indicators obtained to dry weight. Fragmenting was carried out mechanically to the fraction size of $0.5-1 \mathrm{~mm}$, fraction was selected by sequential sieving, using sieves with different cell size. Moisture content was determined by mass variation through wood drying at the temperature of $105^{\circ} \mathrm{C}$ to constant weight [14]. Weighed amounts of disintegrated wood of $1 \mathrm{~g}$ were sampled for further analyses.

Extractive substances were fractioned and removed from wood by sequential extraction with solvents with different polarity, using the Soxhlet apparatus. Distilled water (for water-soluble compounds such as monosaccharides, tannins, etc.) and alcohol-toluene mixture (in 1:2 ratio, for resinous substances) were used as solvents [14]. The content of tannins was determined with a spectrophotometer (PE-5400 UF spectrophotometer, EKROSKHIM, Russia) by optical density of aqueous solution at the wavelength of $277 \mathrm{~nm}$ [15]. Polysaccharides have been extracted by wood material sulfurous hydrolysis (with $\mathrm{H}_{2} \mathrm{SO}_{4}$ concentration of $72 \%$ ) for 2 hours with the subsequent digestion in $\mathrm{H}_{2} \mathrm{SO}_{4}$ concentrated solution [14]. Lignin concentration was determined on dry basis by mass variation. For determination of the share of extractive substances and polysaccharides from dry weight, mass variation was also used [14]. 
Laboratory analyses were carried out in the Laboratory "Ecological Biotechnologies" of Federal State Budgetary Institution of Higher Education "Udmurtia State University" ( Izhevsk).

Mathematical analysis of the study results was carried out with analysis of variance (ANOVA/MANOVA), by the method of multiple comparisons (LCD-test).

\section{Results and Discussion}

Wood is a complex polymeric compound. And, in distinction from synthetic construction materials, it is characterized by environmental friendliness and abundance. At the same time, it is inferior to artificial materials in such an important indicator as strength. Polymeric and biopolymeric materials (CCB, chipboard, OSB, decking, etc.), characterized by high longevity and high strength, are actively used today. The technology proposed will not, possibly, become a full replacement of the existing materials, but it can substantially improve the existing technologies in terms of strength of materials obtained.

The natural wood is a porous structural compound, therefore, it has small specific weight and penetrating power. However, at the same time, porosity reduces the wood strength. Wood pressing will allow to remove cavities from it, however, pressing will be inefficient without lignin removal. In this case, wood permeability will decrease, but at the same time, its strength will increase, and deformation of the obtained material from temperature and moisture will almost disappear.

In order to do this, the line of structural components, responsible for wood strength/hardness, should be removed from wood. As a rule, it is done by hydrolytic digestion with the use of highly-concentrated alkali. According to some researchers, concentration should reach $99 \%$. Now we are working on reducing this concentration with the purpose of the process environmentalization and economic profitability.

It should be noted that this technology has been tested, and it showed exciting opportunities [16]. For example, according to USA scientists, such wood has the following characteristics:

- tensile strength $587 \mathrm{MPa}$;

- increase of dense wood tensile strength is not accompanied by wood impact strength decrease;

- high specific strength (451 $\mathrm{MPa} \mathrm{cm}^{-3} \mathrm{~g}^{-1}$ ), higher than in light titanium alloys (around $244 \mathrm{MPa} \mathrm{cm}^{-3} \mathrm{~g}^{-1}$ );

- moisture resistance - absorption not more than $8.4 \%$.

However, researchers use highly concentrated alkali (99\%) in the process of studies, and do not take into account wood non-structural components (extractive substances), that largely affect wood chemical processing methods and ways.

Following the conducted biochemical analyses of sprucewood, it has been found that the content of extractive substances is $4 \ldots 8 \%$ from wood oven-dry weight (hereinafter, o.d.w.).

The basis of coniferous extractive substances is represented by resinous substances and water-soluble compounds. In total extractive substances, resinous substances dominate over water-soluble ones. The main share of water-soluble extractive substances is represented by polyphenol compounds (Fig. 1). Content of resinous compounds within the range of $4-8 \%$ from wood o.d.w. has been determined (Fig. 2). 

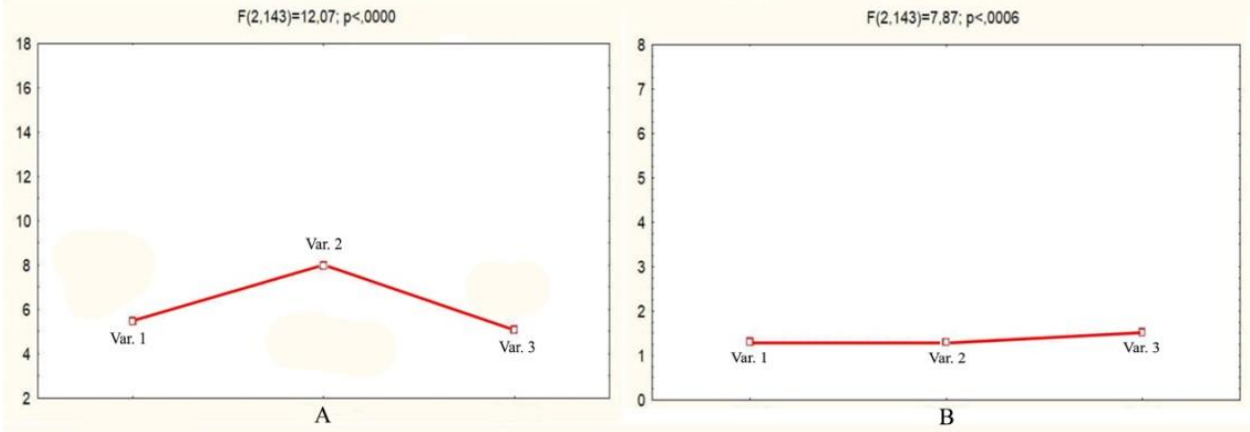

Fig. 1. Content of extractive substances in Siberian spruce wood (A, total content; B, tannins content), $\%$ from wood o.d.w.

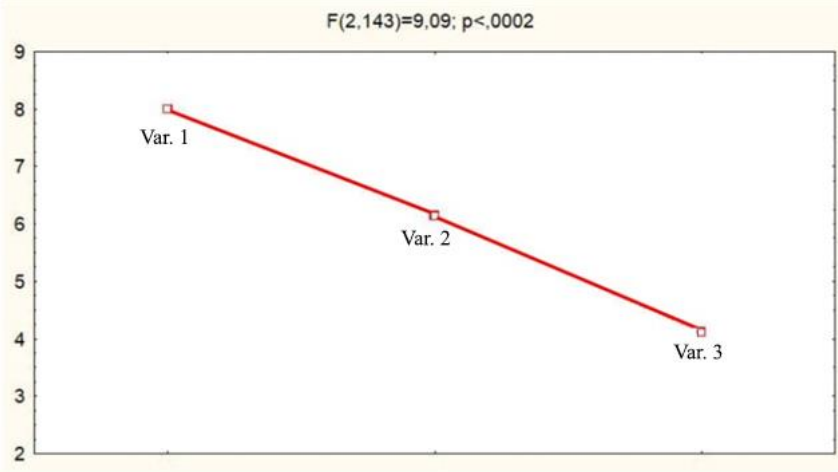

Fig. 2. Content of resinous extractive substances in Siberian spruce wood, \% from wood o.d.w.

Following the results of our studies, we determined that the content of extractive substances is largely influenced by vital condition of plants.

The analysis of extractive substances content in wood of samples with various vital condition, carried out by solvents that do not disrupt the structure of extractive substances, showed that samples with all vital condition categories have the predominant share of resinous substances over phenolic compounds. However, with the deterioration of the plants condition, the share of phenolic compounds increases (Fig. 3).

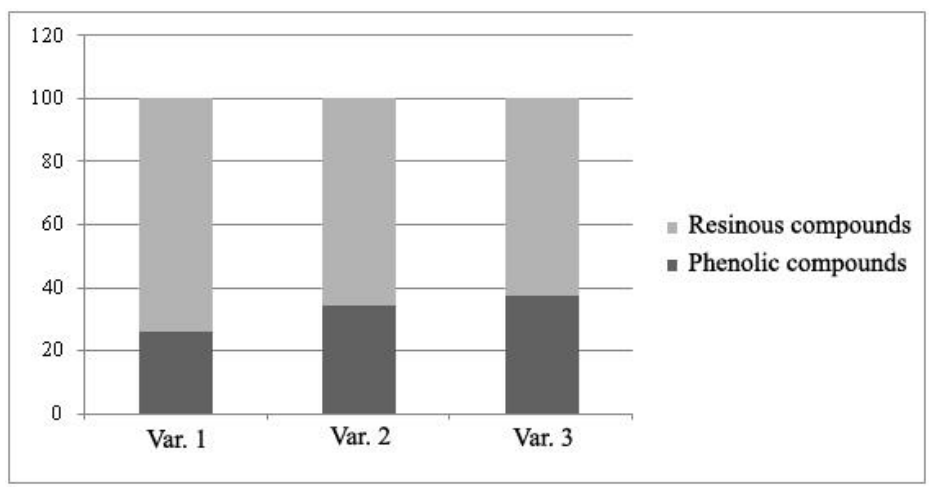

Note: Var. 1 - good vital condition, Var. 2 - satisfactory vital condition, Var. 3 - unsatisfactory vital condition.

Fig. 3. Yield of extractive substances from Siberian spruce wood, \% from wood o.d.w. 
Therefore, the number and composition of wood non-structural components (extractive substances) are influenced by such factor as the condition of plants.

The role of extractive substances in wood of plants is large. These are biologically active compounds, playing the considerable protective role in protection from pathogenic organisms. At the same time, although extractive substances considerably contribute to the formation of stability in plants, their composition and distribution in tissues affect wood properties and its industrial application, making its processing more complicated. The extractive compounds have a negative impact on the cellulose extraction process during digestion [17], and their oxidation results in wood acidity increase, thus contributing to its degradation [18]. According to Várhegyi et al [19], removal of some extractive substances decreases the fixed carbon content, reducing the yield of charcoal and shifting the thermogram to higher temperatures. Wood with high content of extractive substances complicates its chemical processing and deteriorates firewood (pellets, fuel briquettes) [20].

Based on the results of the studies conducted, lignin is extracted from wood the most efficiently after the preliminary removal of extractive substances with alcohol and toluene mixture.

For this reason, the mandatory requirement is the removal of extractive substances from wood, prior to lignin extraction.

With the purpose to decrease toxicity of chemical reagents used and to exclude the extraction of extractive substances from the production process, raw wood should be subject to fungal attack with oyster mushrooms. According to S. Ateş, D.D. Akyildiz, Ç. Olgun (2016) oyster mushroom Pleurotus ostreatus (Jacq.) P. Kumm. can be used for Fagus orientalis Lipsky wood processing with the purpose of decreasing the amount of lignin and extractive substances without any considerable loss of hemicellulose and cellulose [21]. Further studies are required to determine the impact of $P$. ostreatus at pulp properties of other timber species with the purpose to obtain high-strength fibreboards.

\section{Conclusions}

1. With the purpose to implement the concept of rational, multi-purpose and sustainable development of Russian wood complex, it is required to actively involve both woodworking and wood production waste, in particular, non-merchantable wood and nonwood waste (branches, blocks, and roots).

2. Along with conventional wood processing technologies, modern methods of deep pulp processing, based on scientific wood chemistry methods, should be developed.

3. One of prospective methods of obtaining extra strong wood is its hot pressing after lignin removal from wood. Similar material has such characteristics as high tensile strength (587 $\mathrm{MPa})$, high specific strength $\left(451 \mathrm{MPa} \mathrm{cm}^{-3} \mathrm{~g}^{-1}\right)$ and moisture resistance (absorption not more than $8.4 \%$ ). Such characteristics considerably outmatch the existing plate construction material.

4. The efficiency of lignin extraction from wood for subsequent pressing, is largely influenced by non-structural wood components (extractive substances), especially in coniferous species. For example, the share of extractive substances in Siberian spruce wood reaches $8 \%$ from oven-dry weight, where resinous compounds are predominant substances.

5 . With the purpose to decrease toxicity of chemical reagents used at lignin extraction and to exclude the extraction of extractive substances from the production process, raw wood should be subject to fungal attack with oyster mushrooms. For example, the fungus Pleurotus ostreatus (Jacq.) P. Kumm. efficiently decreases the concentration of lignin and extractive substances without any considerable loss of hemicellulose and cellulose. 


\section{Acknowledgement}

The study was carried out with the financial support of the RFBR grant No. 19-04-00353 A.

\section{References}

1. GOST 32567-2013. Wood boards with oriented particles. Specifications (2014)

2. GOST 4598-2018. Fibre boards of wet way of production. Specifications (2019)

3. GOST R 52078-2003. Wood particle boards, laminated with paper impregnated with thermosetting resins. Specifications (2003)

4. GOST 3916.1-2018. Plywood for general use with outer layers of hardwood veneer. Specifications (2019)

5. A.P. Karmanov, Yu.P. Monakov, Uspekhi Khimii, 72, 797 (2003)

6. B.N. Ugolev, Wood Science and Forest Commodity Research (2007)

7. L.L. Leontiev, Wood Science and Forest Commodity Research (2011)

8. K.G. Bogolitsin, V.V. Lunin, Physical chemistry of lignin (2010)

9. R. Vanholme, B. Demedts, K. Morreel, J. Ralph, and W. Boerjan, Plant physiology, 153, 895 (2010)

10. I. I. Rysin et al., Geography of Udmurtia: natural environment and resources (2009)

11. Ministry of Natural Resources and Environmental Protection of the Udmurt Republic, http://www.minpriroda-udm.ru/

12. E.V. Diakova, V.I. Komarov, Mechanical mass technology (2006)

13. A.V. Obolenskaya, Z.P. Yelnitskaya, A.A. Leonovich, Laboratory work in wood and cellulose chemistry (1991)

14. I.A. Samylina, R.K. Aboyantz, E. N. Grinko, Method of tannins determination in vegetable raw materials (2012)

15. J. Song, C. Chen, S. Zhu et al., Nature, 554, 224 (2018)

16. W. He, H. Hu, J. of Wood Chem. and Tech., 33, 52 (2013)

17. A.N Shebani, A.J. Reenem, M. Meincken, Thermochimica Acta, 471, 43 (2008)

18. G.Várhegyi, M.G. Gronli, C. Di Blasi, Ind. Eng. Chem. Res., 43, 2356 (2004)

19. K.E. Vedernikov, I.L. Bukharina, E.A. Zagrebin, Int. Res. J., 11, 61 (2017)

20. S. Ateş, D.D. Akyildiz, Ç. Olgun Kastamonu Uni. Orman Fakültesi Dergisi, 16, 83 (2016) 